\title{
A participatory systems approach to understanding climate adaptation needs
}

\author{
Helen Ross • Sylvie Shaw • David Rissik • Neil Cliffe • \\ Susie Chapman • Vanessa Hounsell • James Udy • \\ Nghia Trong Trinh • Jess Schoeman
}

Received: 26 February 2014 / Accepted: 29 December 2014 / Published online: 17 January 2015

(C) Springer Science+Business Media Dordrecht 2015

\begin{abstract}
Emerging literature on climate adaptation suggests the need for effective ways of engaging or activating communities and supporting community roles, coupled with whole-of-system approaches to understanding climate change and adaptation needs. We have developed and evaluated a participatory approach to elicit community and stakeholder understanding of climate change adaptation needs, and connect diverse community members and local office bearers towards potential action. The approach was trialed in a series of connected social-ecological systems along a transect from a rural area to the coast and islands of ecologically sensitive Moreton Bay in Queensland, Australia. We conducted 'climate roundtables' in each of three areas along the transect, then a fourth roundtable reviewed and extended the results to the region as a whole. Influence diagrams produced through the process show how each climate variable forecast to affect this region (heat, storm, flood, sea-level rise,
\end{abstract}

Electronic supplementary material The online version of this article (doi:10.1007/s10584-014-1318-6) contains supplementary material, which is available to authorized users.

H. Ross $(\bowtie)$

School of Agriculture and Food Sciences and Global Change Institute, The University of Queensland, Brisbane, Queensland, Australia

e-mail: Helen.Ross@uq.edu.au

S. Shaw $\cdot$ J. Schoeman

The University of Queensland, School of History, Philosophy, Religion and Classics, Brisbane, Queensland, Australia

D. Rissik

National Climate Change Adaptation Research Facility, Griffith University, Gold Coast, Queensland, Australia

N. Cliffe

Department of Agriculture, Fisheries and Forestry, Mackay, Queensland, Australia

S. Chapman $\cdot$ V. Hounsell

SEQ Catchments, Brisbane, Queensland, Australia

J. Udy

Healthy Waterways, Brisbane, Queensland, Australia

N. T. Trinh

The University of Queensland, School of Agriculture and Food Sciences, Brisbane, Queensland, Australia 
fire, drought) affects the natural environment, infrastructure, economic and social behaviour patterns, and psychosocial responses, and how sets of people, species and ecosystems are affected, and act, differentially. The participatory process proved effective as a way of building local empathy, a local knowledge base and empowering participants to join towards future climate adaptation action. Key principles are highlighted to assist in adapting the process for use elsewhere.

\section{Introduction}

Emerging literature on climate adaptation suggests needs for effective ways of engaging or activating communities and supporting community roles in climate change adaptation. This has social justice reasons, since local communities may be on the frontline of damaging climate change impacts, and practical benefits since residents and local organisations are intimately connected to local places, and familiar with the locality's particular social, historical and political contexts (Adger et al. 2009; Kohler and Koontz 2008; Moser 2010; Sheppard et al. 2011).

Evidence from studies evaluating the outcomes of consultative processes (e.g. Tompkins et al. 2008 on coastal planning) indicates that involvement of those likely to be affected by policy decisions or climate change uncertainties is critical in galvanising support for policy change and action. It is important in informing local communities about likely change effects, for identifying and dealing with potential risks and vulnerabilities, and also for encouraging and mobilising community activities geared to minimising these risks. Studies have stressed that programs or meetings directed at creating a shared vision amongst community members need people with a willingness to engage with others in open, unfettered and respectful multi-disciplinary discussion (Larsen and Gunnarsson-Östling 2009; Mastrandrea et al. 2010). Such approaches aim to break down the top-down-bottom-up nexus and build an interactive process that engages holistically, incorporating the differing views held by the variety of stakeholders. They should be inclusive and take into account the social, political, psychological and spiritual values and experiences of participants (Kellert 1996), and acknowledge the range of influences on people's understanding of climate change, such as the way the media has reported the issue (Carvalho 2010).

While a substantial and growing literature asserts the need to involve communities in climate change adaptation, there is less information on the practicalities of creating holisticallyframed community dialogue and action around climate change issues (Hobson and Niemeyer 2011). The inclusion of an action focus in stakeholder and community discussions can help overcome a general resistance to change expressed through apathy, lethargy, futility, anxiety, fear or even a sense of guilt about not doing enough (Ferguson and Branscombe 2010). Moser (2006:3) adds that effective deliberations, education and information can help shift individual behaviours and facilitate climate change 'mitigation and adaptation goals' at a community, organisational, political and corporate level. Well designed processes can also help to inform the community, and learning processes can be an in-built feature of initial and ongoing discussions. The ability of communities, individuals and organisations to adapt to climate change depends, in part, on their understanding of key issues, their awareness of the short and long-term effects of change, and their involvement in processes aimed at developing strategies to cope with the likely effects of change (Tompkins et al. 2008; Serrao-Neuman et al. 2011).

In order to be involved in climate adaptation, communities require knowledge and understanding about the potential impacts and risks associated with projected climate changes in their regions and localities. They are also able to contribute local knowledge to the understanding of local level climate impacts to assist in identifying the consequences of a climate impact for local ecology, infrastructure, economy, culture and social interactions (Few et al. 2007).

While governments are doing much to plan and implement climate adaptation, there is a tendency to concentrate on points that governments have mandates to act on (e.g. building and 
modification of infrastructure, improving communications), and neglect issues that lie outside their purview, e.g. building social capital (Adger 2003) or inclusive group identities (Batalha and Reynolds 2012). Further, reliance on specialist and institutional knowledge creates a tendency to form plans in 'silos' (cf Measham et al. 2011). Also, many practitioners consider climate change effects as a separate pressure to be managed, rather than one that interacts with and often exacerbates existing environmental and social pressures and trends.

Given the diversity of and complex interactions within social-ecological systems in any part of the world, a particular climate-induced change (e.g. higher temperatures) may have vastly different influences and consequences in different ecosystems and human communities. This is particularly so since governments, communities and their individual members can respond in a wide variety of ways, influencing the pathways of change in complex ways (Adger et al. 2009; Moser et al. 2010). Thus there is a need to synthesise the social and the ecological, in terms of understanding impacts and planning responses. Taking a whole-of-system approach to underpin climate adaptation planning and effort leads to more comprehensive adaptation approaches and reduces the risk of single-issue efforts creating maladaptations elsewhere across linked issues (Adger et al. 2011).

These two considerations - the need for better ways of engaging communities in climate adaptation efforts, and the need for whole-of-system understandings particularly at local levels where information is weak - are brought together in this study to develop effective approaches to community engagement in climate adaptation, through a process to synthesise community knowledge into local systems understandings of the potential consequences of climate change.

\section{Case study background}

South East Queensland (SEQ) is particularly vulnerable to climatic change (Hennessy et al. 2007). It is the fastest growing region in Australia, with a rapidly increasing population, residential and industrial development; increasing demand for water and power, and intensifying patterns of land use. It includes a system of rivers draining to the ecologically sensitive Moreton Bay (a marine park and Ramsar site); three sand islands hemming the bay, the conjoined cities of Brisbane, Logan, and Redlands as well as parts of the Gold Coast. The upper catchment is dominated by rural land use, including both marginal and highly productive agricultural lands, with expanding lifestyle farming and small-scale tourism. Despite the rapid growth and encroachment on green spaces, the region remains nationally recognised as a biodiversity hotspot being the northern and southern limits of terrestrial and aquatic species, known as the Macleay-Macpherson overlap.

Climate modelling indicates the region is likely to become hotter and drier over the next few decades (Low Choy et al. 2010; Queensland Government 2009). Storms and rainfall are likely to intensify, while sea level will continue to rise. Climate extremes place added pressure on already constrained resources, while extreme weather events such as floods endanger biodiversity, damage infrastructure, and threaten lives and livelihoods especially of the vulnerable (Roiko et al. 2012).

The research area consists of a series of connected social-ecological systems following the LoganAlbert river system. The headwaters are located in forested hinterland, that supports rural activities on the floodplains and lower slopes (the Scenic Rim). The river then flows north easterly through a culturally diverse and low-income peri-urban and urban area (Logan City Council), to the coast and islands of ecologically sensitive Moreton Bay (Redland City Council) (Fig. 1). This transect was chosen to represent the diversity of rural, urban and coastal settings and climate change risks. The Logan-Albert river system has a history of high sediment and nutrient loads and has been identified regionally as a priority river for water quality improvement. Floods in 2008 (Rissik et al. 2008) and 2011 raised community awareness on the impact of extreme weather events. This information-rich 


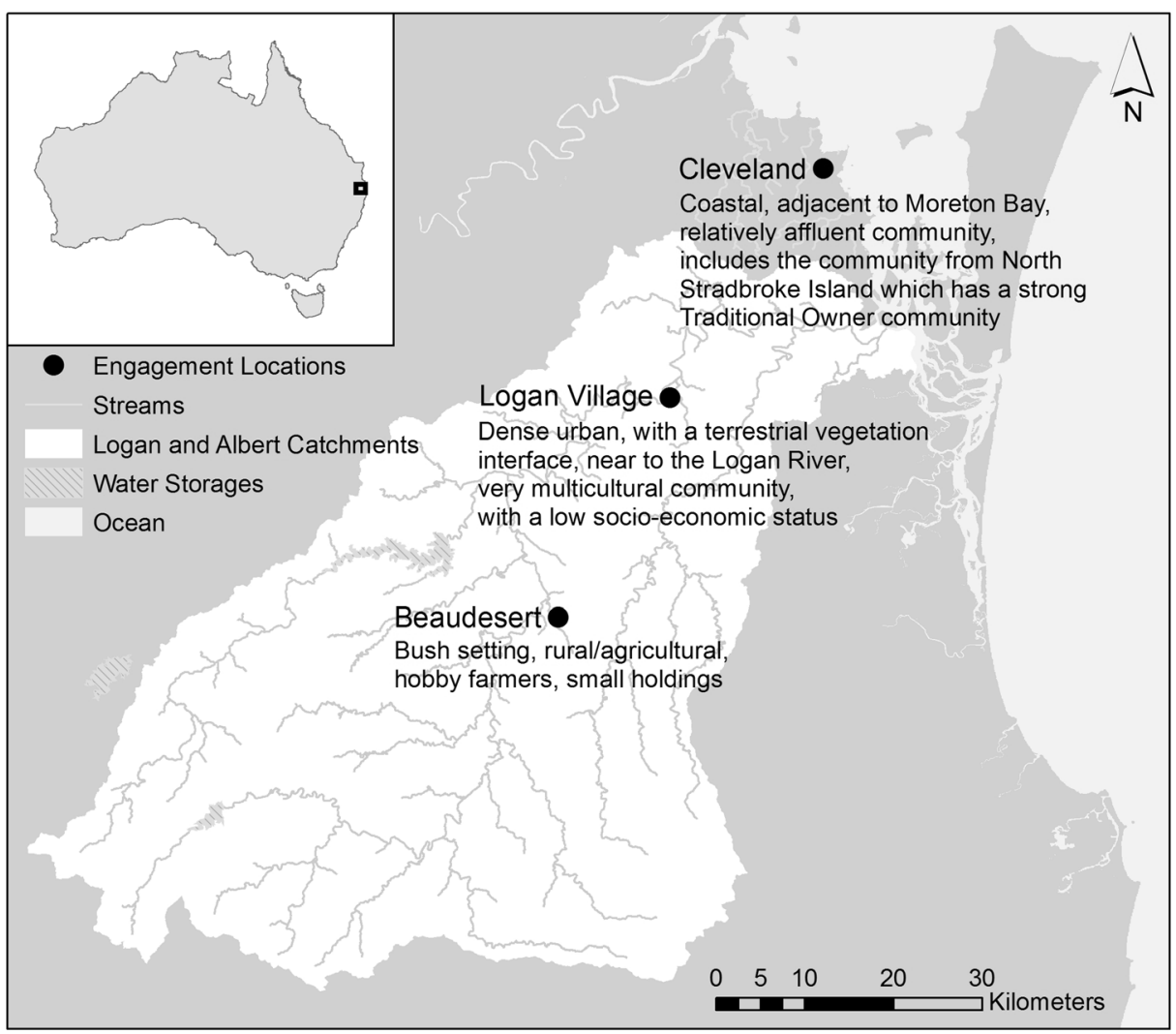

Fig. 1 Study locations and characteristics

transect offered an opportunity to link risks and uncertainties across terrestrial, coastal and marine environments and communities (Álvarez-Romero et al. 2011 on conservation issues), and avoided areas pre-occupied with recovery from the major 2011 flood in the Brisbane River to its north.

While not part of longer-term research or formally connected with any planning processes, the project was designed to build on previous participatory climate research and consultations in SEQ, including community workshops on two Moreton Bay islands (Chapman 2010a and b), the SEQ-Climate Adaptation Research Initiative (McDonald et al. 2010; Roiko et al. 2012) and a large community-based 'climate summit' held in Logan 2 years before this project. At the time of the research there were no local climate adaptation steps happening, that might have proved divisive in the communities. All three local governments were backing off climate adaptation initiatives, owing to election of more conservative councils - an issue that disappointed some participants. A few of the community-based organisations were interested, but not in a position to undertake or lead climate adaptation on their own.

\section{Methods}

This section explains our approach in detail, and summarises key principles for adaptation elsewhere. The approach was designed to support social learning (Cundill and Rodela 2012; Reed 
et al. 2010), and build a sense of collective efficacy (Bandura 2000) among participants at each roundtable, across the transect, and between community members and government organisations. The sequence of each day was designed to set the tone and warm up, inform, elicit and share knowledge, identify action opportunities, evaluate, and wind up on a forward-looking note ( $\mathrm{cf}$ the forming to storming, norming, performing and adjourning stages of group formation, Tuckman and Jensen 1977). It also combines some of the range of public participation options identified in ladders (Arnstein 1969) and spectrums of public participation (International Association for Public Participation IAP2 2014): in this case 'inform', 'involve', and 'empower' but used together rather than as alternate options. We seek however to go beyond these well-known classifications of participatory methods. We accept that more dimensions than power are important in designing participatory processes - especially agency, and duration (Ross et al. 2002). The day was organised to vary the types of activity to align with aural, visual and conative learning preferences.

\subsection{Planning and preparation}

\section{Principles:}

Choose an interdisciplinary, multi-skilled facilitation team

Invest time in careful planning and preparation

Conduct a staged, well-planned selection and invitation process

Recognise diverse knowledge systems associated with different backgrounds, including Indigenous peoples.

Team formation and roles were essential parts of the design and process. Our highly interdisciplinary team included two social scientists, two biophysical scientists with core skills in water research and climate adaptation, an Aboriginal team member well known to all Traditional Owners of the region, and very experienced facilitators with expertise in climate change adaptation and community research in community-based and agricultural extension contexts. Members worked in universities, collaborative organisations responsible for environmental management in the region, and a government department, and had a wide range of community, agricultural and organisational connections.

Team roles were established clearly for each event. A charismatic personality was selected as lead facilitator. The project leader was responsible for opening announcements, and together with the lead facilitator acted as host. Other members led sessions in pairs, according to their main skills, had specific hosting roles (e.g. welcoming), and facilitated at tables. International student volunteers, chosen to given them experience and increase a tone of multi-cultural acceptance, helped with hosting, took photos, and kept supplies of stationery flowing to the tables.

Preparation required 2 days of team planning workshops to decide team roles, locations and participant sampling, and design every aspect of the process. Team members also consulted the environmental and community engagement staff of the three local governments along the transect, and leaders of previous studies.

We established a tiered approach with three local roundtables, along the transect from inland to coast (see Fig. 1), to be followed by a final, whole-of-transect roundtable designed to join up insights and build networks across the three local government areas, and extend to South East Queensland more broadly. This roundtable was designed to bring in participation by key people whose job roles and life perspectives were of a regional rather than a local nature, and to expand connection with organisations in a position to take or support relevant actions.

The events were designed to minimise, then handle, possible conflict in the context of partisan politics about climate change attribution. The participatory events were termed 'roundtables' to convey the constructive, collaborative approach sought. To encourage engagement and alleviate debate about climate change, we emphasised both climate variability and climate change in the briefing and discussions. The process encouraged actions that 
coupled mitigation and adaptation outcomes, thereby addressing the spectrum of opinions on climate change attribution. Each team member was well briefed to handle any conflict that arose on the tables they were facilitating, and the lead facilitator was to take overall responsibility for conflict management if required. (In the event two minor conflicts regarding frustrations with the government were averted at the tables.) Dates were also set carefully, in this case to avoid a period of anticipated 'politicking' around local elections.

A carefully designed selection and invitation process was vital to achieving diversity of participation, intended to represent the spectrum of activity within each local government area rather than any orientation or otherwise towards climate issues. Participants were invited through a staged process, involving stakeholder analysis, web searches, and networking through key organisations. We identified 'sectors' that were typical of each local area, then organisations within each sector, then individuals to invite from those organisations. We included atypical stakeholders, such as multicultural and religious groups, the arts community, and the elderly. Participation thus incorporated Traditional Owners (who if included at all in other processes tend to be offered separate processes rather than opportunities to engage in dialogue with others), environment, agriculture, water utilities, local business, disaster management and local government. Each roundtable reflected the unique social fabric of that local area. The Scenic Rim (rural) roundtable had strong involvement from the agricultural sector. Logan, the peri-urban and urban location had diverse cultural, social and religious organisations, while the Redlands (coastal) event included strong representation from local businesses and industry, including tourism and fishing (see supplementary materials).

Participants were invited by telephone calls, followed up with emails. To ensure explanation of the roundtable purposes was accurate, clear and consistent, two team members rehearsed an invitation script and responses to possible questions and doubts with the socially-skilled assistant who conducted the calls.

The three local roundtables had 23 (Scenic Rim), 22 (Logan) and 26 (Redlands) participants respectively $(65,59$ and $46 \%$ male respectively; the genders were balanced in the regional roundtable, and overall at $53.5 \%$ male and $46.5 \%$ female). The size was appropriate to represent the diversity of each local community, while providing a comfortable scale for networking and discussions. Participants varied in age from early career through to retirees. Local government staff, and the locally-based staff of state organisations such as emergency services, made up $24 \%$ of participation.

The roundtables were held in mid-2012. All venues were chosen to be physically and socially accessible, and were checked before booking. Roundtables lasted five and a half hours including lunch and breaks.

\subsection{Participatory approach: local roundtables}

To help participants' comfort in an unfamiliar environment, the assistant who had invited them over the phone welcomed them on arrival. Participants self-selected their seating at circular tables of six to eight people per table.

\subsubsection{Introductions (forming)}

\section{Principles:}

Recognise cultural norms, honour local leadership

Orient participants

Start forming relationships

Provide a fun, physically active introduction. 
Each climate roundtable began with a welcome from, or acknowledgement of, the Traditional Owners of that area. This was followed with a welcome from the project leader and a reminder of the purpose of and desired outcomes from the roundtable, explanation of some key terms (e.g. the emphasis on climate variability and climate change), and the lead facilitator's 'roadmap for the day'. Then came the research ethics process and signed consent to participate, then an introductions exercise requiring participants to get up and move outside, and an 'ice-breaking' exercise.

\subsubsection{Climate timeline (norming)}

\section{Principles:}

Start eliciting and acknowledging participants' knowledge before any science presentations Build confidence in their own knowledge, and pleasure in sharing insights.

This activity was designed to make the climate issues familiar and non-threatening, and continue the participant introductions. It emphasised the importance of climate variability (diverting attention from whether participants accepted the existence of climate change), and primed participants to recognise the extent of their knowledge and experience of climate extremes. Participants were asked to recall significant climatic events over their lifetime in the area where the roundtable was being held. After individual reflection they shared within their small-group tables, then each table reported findings to the larger group. These climatic events were recorded on a hand-drawn timeline on a whiteboard. The facilitator asked participants for any particular observations or trends they could identify (responses included sharper transitions between wet and dry periods, fewer afternoon storms, and a 6 week shift in the asthma season).

\subsubsection{Climate briefing (norming)}

\section{Principles:}

Some science briefing is necessary to even up levels of knowledge, explain necessary terminology, and (for some) answer a thirst for more information

Be informative but not too detailed

Present science information after participants have begun sharing theirs; try to present as complementary to rather than superior or more informed than local knowledge.

A presentation by a biophysical science team member outlined the latest climate projections for SEQ. This aimed to set the scene for collective participant understanding, and introduce scientific information on key climate impacts such as increased incidences of drought, heatwaves, greater risk of fire, increased intensity of storms and floods, and sea level rise. Adaptation and other key concepts were defined and explained. Effort was made to present the information in plain English and non-scientific terms. The timing of this session was particularly important: early in the day, but not so early that participants felt the event was 'science-led'.

\subsubsection{Brainstorm (norming to storming)}

\section{Principle:}

Defuse passions by allowing people's key points to be heard and noted early.

This session gave participants an opportunity to share first impressions and air 'burning issues' before entering more detailed sessions. It was designed to continue the familiarisation process, and manage group dynamics so that points that people were particularly passionate about would be recorded early, encouraging everyone to relax and listen to one another in the following sessions. It also brought out people's sense of urgency to mitigate climate change, so that this energy could be directed into discussion of adaptation without being dismissive or divisive. 
Participants brainstormed in groups around each table. They discussed their concerns, feelings, observations, and risks and opportunities around climate variability and change within and across the region. Maps were provided on the walls and tables for reference. A spokesperson from each group then reported their key points to all participants.

\subsubsection{Systems analysis through influence diagrams (performing)}

\section{Principles:}

Elicit systems knowledge through an enjoyable, feasible process

Group sizes of five to six people work well

Provide for physical action.

The next session was the key to eliciting systems understandings, based on local knowledge, about the potential influences of each climate variable within the local area. Participants self-selected into working groups of five to six people each, based on their interest in specific and significant climate variables - drought, heat, fire, floods, storms or sea level rise. Following a brief demonstration of the approach using themes from their earlier dialogue, the groups worked together to construct 'influence diagrams' on white polyester shower curtains sprayed with an adhesive and hung around the walls. Using cards, the groups were encouraged to note effects on ecosystems, communities, families and individuals, livelihoods, infrastructure and the economy, and to show how these impacts connect through multiple pathways. One team member assisted each group, lightly facilitating where required but not guiding strongly.

When each diagram was complete, participants were asked to study the other groups' diagrams, question and validate, and add new ideas or influences to them. This enabled all participants to contribute on each climate variable. The newly added cards, and those that clearly showed proposed actions (interventions) rather than direct parts of an influence pathway were identified with symbols.

\subsubsection{Key opportunities for adaptation (performing, looking towards adjourning)}

\section{Principles:}

Communities seek outcomes, and do not welcome 'talkfests' that do not lead towards action.

This session focused on ideas and opportunities for building resilience and adapting to climate change impacts. It was designed to enable participants to build from the systems analysis towards action opportunities that they, or other organisations, could pursue. (The research team had no role to implement actions). This recognised the importance participants attach to having participatory processes lead to action.

Still in groups based on their chosen climate extremes, the participants returned to their tables and canvassed key concerns and priorities emerging from their influence diagrams. They recorded their priorities on butchers paper and reported these back to the larger group.

To achieve engagement and integration, it was also important to acknowledge and validate actions that were currently and historically underway that were effectively climate adaptive but may not be termed as such, or not seen as part of the collective sum of solutions.

\subsubsection{Close and evaluation (adjourning)}

\section{Principles:}

Inform of future steps and expected outcome

Evaluation is important. 
Participants were thanked, asked for final comments, told of the future steps for the project, and invited to express interest in attending the region-wide climate roundtable. They completed a one-page evaluation questionnaire, noting whether they were willing to be contacted by phone for further evaluation some months later.

\subsection{Region-wide climate roundtable}

\section{Principles:}

Design to connect across local, and local with regional perspectives and networks

Continue momentum built at the local roundtables

Involve potential actors (more of these are focused at regional scale)

Take care with event size: being inclusive may trade-off against the success of each exercise.

Try to keep everyone involved all of the time.

The final, region-wide climate roundtable was conducted 1 month after the last of the three local roundtables. The 56 participants comprised 18 returning from the local roundtables (a third of this roundtable, and about a quarter of the original participants) and 38 new participants with regional perspectives e.g. in regional planning, health, research and government departments.

A similar process to the first three events was followed, with additional elements focused on finding connections and interactions between the three local areas in order to complete the systems understanding. The initial briefing explained the preceding roundtables' process and findings, using photos which also served to refresh returning participants' memories and provide interest.

In preparation, all of the influence diagrams from the local roundtables were redrawn electronically using the Vensim program (by Ventana), and the pathways of influence clarified where linkages seemed unclear. They were then amalgamated, creating combined pathway diagrams for each climate variable (across all three locations). To retain the feeling of immediacy created by the original diagrams, and allow this set of participants to make additions and edits, student volunteers replicated the combined influence diagrams on the sticky fabric. Groups studied the combined diagrams, amending them as they saw fit (few amendments were needed).

The final session brought the roundtables towards synthesis. Participants focused on working together in sectoral groups to investigate linkages between regional areas, between social and ecological changes, and across the range of organisations that had participated. They then considered what partnerships and actions are needed between the different organisations and regions to achieve a desired outcome, for example: How could agricultural organisations work together to improve food security? Or how could cultural groups use their connections to create more awareness about the causes of climate change and its likely effects?

This event was more challenging than the local roundtables. Owing to demand we included many more people than originally envisaged, and the larger sized group made it harder to keep everyone engaged throughout each activity. One new exercise designed to link findings across the climate variables and across the three local areas could not involve everyone at the same time, and those not actively involved at all times became disengaged but spent time networking. This did not deplete the outcomes of the exercise, but planning for such workshops should consider how large groups may respond.

\subsection{Evaluation}

Evaluation was conducted in two stages. The one-page questionnaire at the end of each roundtable asked about previous interest in understanding climate adaptation issues, increases 
in interest and understanding as a result of the roundtable, and success or otherwise in meeting some of the aims of the roundtable (see supplementary materials).

Those contacted by phone 6 months later were asked a series of questions related to the roundtable process, what they had gained or learnt from the process, whether they had changed their viewpoints about climate change impacts, and whether they, or their organisations, had undertaken any action as a result of the roundtables.

Both evaluations were conducted by a mature-age student who participants had met at the roundtables, and who had observed each process, but was explicitly independent of the design and delivery team. Results are summarised below and in supplementary materials.

\subsection{Dissemination}

Participants requested and were provided with a set of participant contact details to help them in their intended cooperation, and the science briefing powerpoint. A twelve-page synthesis report, attractively desktop-published, was circulated to all participants as soon as analysis was completed, and lodged on the funding body's website (see supplementary materials).

\section{Results: local knowledge}

Influence diagrams showed how each climate variable forecast for this region was thought to affect the natural environment, infrastructure, economic and social behaviour patterns, and psychosocial responses together, and how sets of people, species and ecosystems are affected, and act, differentially in each place. The study team made no presumptions about the accuracy or otherwise of the knowledge expressed, but it accorded well with the biophysical and social scientists' knowledge and some clearly drew on publicly available knowledge. The influence pathways were seen as accentuating current trends and concerns, such as the building of planned new towns to accommodate rapid population growth in the region, thus reducing wildlife habitat. Table 1 illustrates some of the types of influence identified by the roundtables (see also supplementary material). Since the information on the diagrams was complex, and difficult to represent in a readable way, each chain of influence has been rendered here in prose so as to give a sense of how one variable leads to others in a series of steps.

The influence diagrams showed that participants were able to link a wide range of ecological, infrastructure, financial, social and psychological factors in perceived chains of influence. This contrasts with the sectoral approach often taken by governments in approaching climate change impacts and adaptation (e.g. Queensland Government 2011). Their responses were clearly informed by experience of extreme events in their local areas, and by knowledge of their areas and people, but also drew at times on generic information (e.g. well reported global effects of sea level rise). A limitation is that the labels alone are sometimes hard to interpret out of context, do not necessarily convey the logic expressed by the participants as they compiled the diagrams, and the facilitators found it hard to record the conversations at the same time as assisting. Different results should be expected in other places.

The influence diagrams also give a sense of the participants' values and priorities. Protection of waterways, land clearing for new towns, and the additional risk of climate changes to existing concerns about wildlife, featured strongly. There was also awareness of connections between areas along the transect, particularly upstream-downstream effects. In all, the influence diagrams convey a strong awareness of each local area as a social-ecological system, connected with others within their region through the waterways and other interdependencies. 
Table 1 Examples of influence pathways (see supplementary materials for full diagrams)

Scenic Rim (rural) - more severe, Logan (urban) - more intense Redlands (coastal) - sea level rise prolongued droughts storms

- Reduced stream flows create chains of isolated ponds. As a result, eels, platypus and invertebrates are unable to migrate.

- There is less moisture in leaves for koalas and other leaf-eating fauna.

- Reduced flows affect water quality in dams and weirs, increasing the risk of algal blooms and salinity, and threatening the supply of drinking water.

- Drought leads to more intense fires, endangering people and the built and natural environments.

- Stress on biodiversity makes areas, particularly waterways, less desirable for tourism and recreation.

- Loss of recreation and sports activities, particularly fishing, may lead to psychological stress in certain sectors of the community.

- Economic activity declines, leading to further psychological and financial stress.

- The politics of drought subsidies also contribute to psychological stress.
- More state emergency service volunteers are required. They need to be fit, to qualify. Few people are fit enough owing to a lack of participation in sport.

- High cost of storm recovery reduces budgets for other purposes.

- Industry suffers damage e.g. from flood transfer of toxic materials, but also has opportunities for growth e.g. green careers

- Storms at 3-4 pm (a typical time in this climate) prevent children getting home from school. This links to adequacy of infrastructure; risk of loss of life as parents take risks to collect children.

- Well communicated disaster plans are needed, and not just online as power and broadband are lost.

- Pets go missing, families call emergency services for help. Electricity goes out, road transport is dangerous. These affect mental health, and stretch emergency services.

- There is loss of local farm production. A 3 day interruption in supplies threatens food access. Specific crops are vulnerable.

- Dumping of vegetation and building waste affects rivers, which go up and down quickly. Flora and fauna suffer from habitat loss (Logan River). The waste water overflow threatens households, creating increased load on state emergency services and ambulances.
- Rate of change may be too fast for flora and fauna. Food supplies may not keep up with habitat change.

- Shifting sands affect habitat (see above), lead to erosion (an island location named)

- Storm surges compound sea level rise, leading to loss of or needs to shift infrastructure (roads, drainage, power). They also inundate properties, leading to increase in insurance premiums.

- Salt water intrusion to wetlands and salt marsh mangroves leads to:

Impacts on koala habitat, frogs and other fresh-water dependent life.

Impacts on sea life and feeding grounds, e.g. dugongs may cause loss of tourism potential. Also has impact on waders with loss of high tide roosts.

- Fresh water wetlands will become saline mangroves, with net loss of fish habitat. Built marine infrastructure can become fish habitat. There may be species change with stable overall productivity; may change food sources for humans. Meanwhile mangrove rehabilitation buffers wave energy.

\section{Evaluations}

\subsection{End of day evaluation}

These 95 responses (75\% of all participants, some having left early) showed that all participants were interested in understanding climate adaptation issues before attending a roundtable, yet $94.7 \%$ found that the roundtable they attended had increased their interest ( $57.9 \%$ much or very much more, interested). Ninety-seven per cent stated the roundtable had helped to improve their general understanding of climate change issues and $84 \%$ thought the roundtable had changed preconceptions they had about climate change issues. All felt the day 
had succeeded in achieving the roundtable's aim of sharing understandings about what could happen in their area under climate variations. Eighty-nine per cent noted the roundtable had helped them to extend their networks.

\subsection{Follow up evaluations}

These 38 responses (30\% of the original participants) were in most cases overwhelmingly positive. Participants commented on the way the roundtables had 'improved' their awareness, affirmed or reinforced their understanding of the complexity and unpredictability of climate variability and extreme weather events, and heightened their knowledge of the linkages between social and ecological effects, and linkages across the region, from one location to others. Several referred to the importance of the scientific presentation on potential climate change impacts in SEQ, and elaborated on points they had found interesting. Others highlighted the construction of the influence diagrams, and the communication and information sharing that emerged through that process. Many mentioned that their thinking had changed. Participants spoke about the level of collaborative discussions and interactions, how the roundtables had allowed them to meet others across the region and to network, how they had enjoyed the process which some said was well-organised, congruent and provided greater information and understanding on adaptation and the need to develop community-based self-reliance.

Twenty-one participants $(55 \%)$ identified actions stimulated by the roundtables, even if modest initial steps, and 10 others (26\%) were already taking, but continuing actions. Actions included attending and raising climate change issues at conferences, seminars and workshops, adopting climate change awareness programs or policies on sustainability and waste management in their workplaces and organisations, planting trees, and devising ways to reduce their carbon footprint and promote environmental responsibility at home and in the community. The roundtables had directly influenced State Emergency Service planning in the Scenic Rim (on flooding) and informed it in Logan with the realisation of specific impacts of heat waves on the elderly.

Some participants requested the roundtable process should continue, or at least go online with updates; some looked to different ways to get the message out, while others questioned the need for an ongoing process or wondered how the roundtables (both process and information) could assist the community or be applied in a practical way to inform local government on specific issues.

Together these findings meet Reed et al. (2010) criteria for social learning to have occurred: demonstrate that a change in understanding has taken place in the individuals involved (at a surface or deeper levels), and go beyond the individual to occur through social interactions and processes between actors e.g. within a social network.

\section{Discussion}

The imperative for local participatory approaches to climate adaptation is manifold. Knowledge about the climate changes in prospect anywhere remains too broad to provide a strong basis for local planning (Scott and Weston 2011), and is frequently fragmented. The impacts of climate change on our local areas and communities are complex, intersecting and compounding, and require an integrated approach involving communities and all levels of government, especially local government. Communities need to be able to interpret the impacts of climate change in ways that have local meaning, and since they and succeeding generations are directly affected, deserve a leading role in designing actions. This requires 
appropriate 'learning spaces' (Tschakert and Dietrich 2010). However the politicization of climate change, in Australia and elsewhere, has worked against productive community discussion to collectively address the issue. Effective collective adaptation to climate change requires shared understandings of the potential impacts and risks, gained by informed presentation and discussion with other participants. In this context, effective and inclusive participatory processes can build the empathy necessary to overcome divisions that exist around climate change and adaptation, and assist communities to build the knowledge base and collective action needed to move forward.

The participatory process outlined here is designed to fill the gaps in locally applicable knowledge (Scott and Weston 2011), in processes for discussion of climate adaptation (Hobson and Niemeyer 2011). It is based on participatory philosophies of social learning (Cundill and Rodela 2012; Reed et al. 2010), and aims for 'empower' blended with 'inform' and 'involve' on the spectrum of public participation (IAP2 2014). Science input was carefully staged to support, rather than dominate, community process (Rauschmayer and Wittmer 2006). Generic elements suited for adaptation elsewhere are:

- an interdisciplinary team including strong facilitation skills

- a transect approach to selection and connection of locations (optional)

- detailed planning

- strategic and careful recruitment of diverse participants, with a welcoming, well-rehearsed invitation process

- on the day, a staged and engaging process of including cultural protocols, building confidence, providing additional information, eliciting systems understandings, identifying priorities for action, and connecting people in a way that would assist them to take that action

- evaluation.

The positive reception and productivity of our four roundtables shows that local people and local knowledge can contribute, alongside science, government and other sources, to developing a comprehensive understanding of climate change processes in their areas. Our approach of local then regional discussion helped understanding of how one issue or adaptation strategy in one place affects others within and beyond each location, for instance upstream-downstream effects. It appears that the process also built, at least temporarily, a sense of 'collective efficacy' (Bandura 2000) and may have assuaged potential conflicts somewhat by forming an inclusive local identity - at least short-term - transcending sub-group identities (Batalha and Reynolds 2012).

There were some limitations. In the key knowledge-elicitation part of the process, the influence diagrams, only succinct statements could be recorded, and these require support from the detail of the participants' discussion. There was also some imbalance between the ecological, built environment and psychosocial effects of climate change with least emphasis placed on the psychosocial. In the final round table, large numbers made it difficult to keep everyone engaged at some stages, though the wider networking opportunity had advantages.

Evaluations confirmed that the process had been popular and useful from most participants' perspectives. The positive experiences evident at each event, and evaluations, showed that the project has developed an effective and stimulating process to elicit local knowledge and understandings, activate local interest, and build on social networks towards anticipation of and planning for climate variability and climate change. An illustration of the value of the inclusive invitation process is a Pacific Islander pointing out that Logan, already home to a large Pacific community, would be the natural migration destination from Pacific Islands 
affected by sea level rise. Most importantly, in identifying locally agreed priorities for action, related to their local knowledge and particular concerns, the participants have made substantial steps towards creating an action agenda for their areas and region, for their own use and that of local and state government, major businesses and emergency services.

Use of this or any other participatory approach needs to be mindful of known challenges in the use of participation. The issues of sincerity or tokenism in participatory processes (Few et al. 2007), of exhausting over-participation for some (Wondolleck et al. 1996), of unbalanced power relationships (Arnstein 1969), and potential capture of processes by certain groups, are as pertinent in a climate adaption context as any other. As Ross et al. (2002) argue, different parties may have 'agency' over an issue, and this affects the carriage and conduct of a participation process. Much of the literature on participation is written to advise a party responsible for decisions, especially government, as to how it can invite and manage participation from others - rather than working closely with "grassroots" (Few et al. 2007). By contrast Aslin and Brown (2004: 3), distinguish community engagement, "processes and practices in which a wide range of people work together to achieve a shared goal guided by a commitment to a common set of values, principles and criteria”. They point out (2004: 5) that people may be consulted, participate in something, yet not be engaged in the sense of the subject capturing their attention and having meaning for them. Our process aimed to engage, especially across spaces where agency and leadership may be unclear, and to empower towards collective leadership and action.

\section{Conclusions}

The principles and procedures outlined in this paper support productive social learning towards community based understanding, planning options and motivation to underpin climate change adaptation. Social networks that develop through such processes can be beneficial in their own rights, building social capital (Adger 2003), and may assist action on the ground, particularly in circumstances where there are no clear roles for local communities, and government leadership or willingness to include communities is lacking. A single process cannot achieve major steps forward, especially in a short time frame, but can be part of momentum to connect and empower community capacities towards meaningful roles in climate adaptation.

Acknowledgments This is a research initiative of and financed by the Global Change Institute at The University of Queensland. We acknowledge and thank the Traditional Owners, the participants in the four roundtables, officers of the Scenic Rim Regional Council, Logan City Council and Redland City Council for their support, briefings, and advice, and student volunteers Nghia Trinh, Paul Njeruh, Teboho Martins, Van Le, and Guisselle Castillo Coila. We also thank SEQ Catchments for Fig. 1, and anonymous reviewers for their advice.

\section{References}

Adger WN (2003) Social capital, collective action, and adaptation to climate change. Econ Geogr 79:387-404 Adger WN, Brown K et al (2011) Resilience implications of policy responses to climate change. WIREs Clim Change 2:757-766

Adger WN, Dessaoi S et al (2009) Are there social limits to adaptation to climate change? Clim Change 93:335-354

Álvarez-Romero JG, Pressey RL et al (2011) Integrated land-sea conservation planning: the missing links. Annu Rev Ecol Evol Syst 42:381-409

Arnstein SR (1969) A ladder of citizen participation. J Am I Plan 35:216-244 
Aslin HJ, Brown VA (2004) Towards whole of community engagement. Murray-Darling Basin Commission, Canberra

Bandura A (2000) Exercise of human agency through collective efficacy. Curr Dir Psychol Sci 9:75-78

Batalha L, Reynolds KJ (2012) ASPIRing to mitigate climate change: superordinate identity in global climate negotiations. Polit Psychol 33:743-760

Carvalho A (2010) Media(ted) discourses and climate change: a focus on political subjectivity and (dis)engagement. WIREs Clim Change 1:172-179

Chapman S (2010a) Climate proofing Bribie: a climate adaptation action plan. SEQ Catchments Ltd., Brisbane

Chapman S (2010b) South-East Queensland climate proofing demonstration project: a descriptive analysis of three coastal case studies. SEQ Catchments Ltd. and University of the Sunshine Coast, Queensland

Cundill G, Rodela R (2012) A review of assertions about the processes and outcomes of social learning in natural resource management. J Environ Manag 113:7-14

Ferguson MA, Branscombe NR (2010) Collective guilt mediates the effect of beliefs about global warming on willingness to engage in mitigation behaviour. J Environ Psychol 30:135-142

Few R, Brown K, Tompkins EL (2007) Public participation and climate change adaptation: avoiding the illusion of inclusion. Clim Pol 7:46-59

Hennessy K, Fitzharris B et al (2007) Australia and New Zealand. In: Parry M, Canziani O et al (eds) Climate change 2007: impacts, adaptation and vulnerability. Contribution of Working Group II to the Fourth Assessment Report of the Intergovernmental Panel on Climate Change. Cambridge University Press, Cambridge

Hobson K, Niemeyer S (2011) Public responses to climate change: the role of deliberation in building capacity for adaptive action. Global Environ Chang 21:957-971

International Association for Public Participation (IAP2) (2014) Spectrum of Public participation, viewed 7 September 2014. http://c.ymcdn.com/sites/www.iap2.org/resource/resmgr/Foundations_Course/IAP2_P2 Spectrum.pdf. Accessed 15 January 2015

Kellert S (1996) The value of life. Biological diversity and human society. Island Press, Washington DC

Kohler B, Koontz TM (2008) Citizen participation in collaborative watershed partnerships. Environ Manag 41: $143-154$

Larsen K, Gunnarsson-Östling U (2009) Climate change scenarios and citizen-participation: mitigation and adaptation perspectives in constructing sustainable futures. Habitat Int 33:260-286

Low Choy D, Baum S et al (2010) Climate change vulnerability in South East Queensland: a spatial and sectoral assessment, report for the South East Queensland Climate Adaptation Research Initiative. Griffith University, Queensland. http://www.griffith.edu.au/_ data/assets/pdf_file/0006/464298/Griffith-UniversitySEQCARI-Vulnerability-Assessment-Oct-2012.pdf. Accessed 14 January 2015

McDonald J, Baum S et al (2010) Climate change adaptation in South East Queensland human settlements: issues and context, report for the South East Queensland Climate Adaptation Research Initiative. Griffith University, Queensland. http://www.griffith.edu.au/_data/assets/pdf_file/0013/216130/SEQCARI-IssuesPaper.pdf. Accessed 14 January 2015

Mastrandrea MD, Heller NE et al (2010) Bridging the gap: linking climate-impacts research with adaptation planning and management. Climate Change 100:87-101

Measham TG, Preston BL et al (2011) Adapting to climate change through local municipal planning: barriers and challenges. Mitig Adapt Strateg Glob Chang 16:889-909

Moser SC (2006) Talk of the city; engaging urbanites on climate change. Environ Res Lett 1:1-10

Moser SC (2010) Now more than ever: the need for more societally relevant research on vulnerability and adaptation to climate change. Appl Geogr 30:464-474

Moser SC, Ekstrom JA, Kasperson RE (2010) A framework to diagnose barriers to climate change adaptation. Proc Natl Acad Sci U S A 107:22026-22031

Queensland Government (2009) Climate change in the South East Queensland region, Queensland Government, Australia. http://www.ehp.qld.gov.au/climatechange/regional-summaries.html. Accessed 1 Dec 2012

Queensland Government (2011) Climate change: adaptation for Queensland issues paper, Queensland Australia: Queensland Government Department of Environment and Resource Management. http://www.ehp.qld.gov. au/climatechange/pdf/adaptation-issues-paper.pdf. Accessed 15 May 2013

Rauschmayer F, Wittmer H (2006) Evaluating deliberative and analytical methods for the resolution of environmental conflicts. Land Use Policy 23:108-132

Reed M, Evely AC et al (2010), What is social learning? Ecol Soc 15: 4: r1. http://www.ecologyandsociety.org/ vol15/iss4/resp1/

Rissik D, Costanzo S et al (2008) Synthesis report of the flood event in the catchment of the Logan and Albert estuaries, January 2008. Healthy Waterways Partnership, Brisbane 
Roiko A, Mangoyana RB et al (2012) Socio-economic trends and climate adaptation: the case of South East Queensland, Australia. Aust J Environ Manag 19:35-60

Ross H, Buchy M, Proctor W (2002) Laying down the ladder: a typology of public participation in Australian natural resource management. Aust J Environ Manag 9:205-217

Scott J, Weston C (2011) The pitfalls and promises of climate adaptation planning. Aust J Environ Manag 18:8387

Serrao-Neuman S, Harman B, et al (2011) Planning for climate change adaptation: a review of current initiatives in Australia. Griffith University, Queensland, Australia. http://www98.griffith.edu.au/dspace/handle/10072/ 40787. Accessed 1 Dec 2012

Sheppard SRJ, Shaw A et al (2011) Future visioning of local climate change: a framework for community engagement and planning with scenarios and visualization. Futures 43:400-412

Tompkins E, Few R, Brown K (2008) Scenario-based stakeholder engagement: incorporating stakeholders preferences into coastal planning for climate change. J Environ Manag 88:1580-1592

Tschakert P, Dietrich K (2010) Anticipatory Learning for Climate Change Adaptation and Resilience. Ecol Soc 15(2):11, http://www.ecologyandsociety.org/vol15/iss2/art11/

Tuckman BW, Jensen MAC (1977) Stages of small-group development revisited. Group Organ Stud 2:419-427

Wondolleck JM, Manring NJ, Crowfoot JE (1996) Teetering at the top of the ladder: the experience of citizen's group participants in alternative dispute resolution processes. Sociol Perspect 39:249-262 